Revista Española de la Transparencia

Núm. 9. Segundo Semestre 2019

ISSN 2444-2607. Págs. 69-96

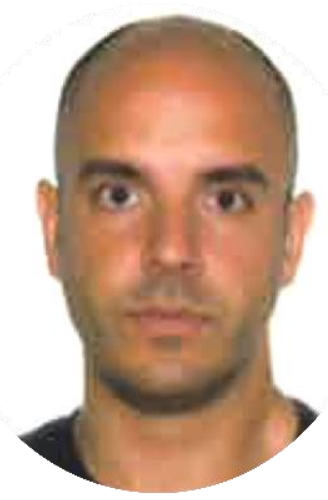

Óliver Garcia Muñoz ${ }^{1}$

Secretaria de Transparència i Govern Obert

Generalitat de Catalunya

\title{
El concepto de información pública en la Ley 19/2013, de 9 de diciembre, y en la Ley del Parlamento de Cataluña 19/2014, de 29 de diciembre, de transparencia, acceso a la información pública y buen gobierno: un análisis comparado
}

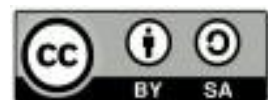 \\ RECIBIDO: 3 de julio de 2019 \\ ACEPTADO: 1 de agosto de 2019
}

RESUMEN: Las leyes estatal y catalana reguladoras del derecho de acceso a la información pública adolecen, en diferente medida, de cierta ambigüedad en cuanto a la determinación del objeto de este derecho, puesto que manejan conceptos indeterminados como el de «información pública», el de «acción previa de reelaboración» o el de «tarea compleja de elaboración o reelaboración» que, lejos de ofrecer significados ciertos, generan incertidumbre entre sus destinatarios.

Este artículo tiene por objeto identificar los problemas interpretativos que la indefinición de los conceptos legales referidos supone para la resolución de las solicitudes de acceso a la información pública, así como recoger y analizar algunos

\footnotetext{
${ }^{1}$ Òliver Garcia Muñoz es licenciado en derecho por la Universitat Pompeu Fabra. Después de cursar diversos estudios de posgrado y doctorado en la misma universidad, colaboró en el despacho Uría y Menéndez. Es autor de una monografia y de varios articulos y colaboraciones en obras jurídicas, a la vez que imparte docencia y participa en seminarios y actividades formativas. Desde 2010 es funcionario del Cuerpo Superior de la Administración de la Generalitat de Catalunya, en la que ha ocupado, entre otros, el cargo de jefe del Servicio de Derecho y grupos de interés. Actualmente es analista en transparencia y buen gobierno en el Departamento de Acción Exterior. Relaciones Institucionales y Transparencia y es miembro del Comité Asesor de Ética Pública de la Administración de la Generalitat de Catalunya.
} 


\section{Oliver García Muñoz}

de los criterios doctrinales que los órganos de garantía del derecho han establecido con la finalidad de concretar los conceptos y orientar asi a las personas responsables en su aplicación.

PALABRAS CLAVE: Información pública. Documento. Datos. Derecho de acceso. Sujetos obligados. Elaboración. Reelaboración. Inadmisión.

CONTENIDOS: 1.- Introducción. 2.- Ámbito objetivo del concepto. 2.1.- Información y documentos: distinción. 2.2.- Prexistencia de los datos y necesidad de una mínima elaboración previa de la información. 2.3.- Limites al deber previo de elaborar la información. 2.4.Información más allá de la que debe ser publicada de forma activa. 2.5.- Información más allá de cualquier procedimiento, registro o archivo. 2.6.- Exclusión de información auxiliar o de apoyo. 3.- Perspectiva subjetiva del concepto de «información pública». 3.1.- Sujetos obligados a tramitar las solicitudes de acceso. 3.2.- Criterios de atribución de la competencia para tramitar y resolver las solicitudes de acceso. 3.3.- Información «en poder» de los sujetos obligados: concepto amplio. 4.- Ausencia de condición de «información pública». 5.Conclusiones.

\section{The concept of public information in Law 19/2013, of December 9, and in the Law of the Parliament of Catalonia 19/2014, of December 29 , on transparency, access to public information and good governance: a comparative analysis}

ABSTRACT: The state and catalan laws that regulate the right of access to public information suffer, in a different way, certain ambiguity regarding the determination of the object of this right, since they handle indeterminate concepts such as "public information", "previous action of re-elaboration" or "complex task of elaboration or re-elaboration" that, far from offering certain meanings, generate uncertainty among its addressees.

The purpose of this article is to identify the interpretative problems that the lack of definition of the legal concepts referred supposes for the resolution of requests for access to public information, as well as to collect and analyze some of the doctrinal criteria that the guarantee bodies of this right have established in order to specify the concepts and guide the responsible people in their application.

KEYWORDS: Public information. Document. Data. Right of access. Subjects obliged. Elaboration. Re-elaboration. Inadmissibility. 


\section{El concepło de información pública ...}

\section{INTRODUCCIÓN.}

El presente trabajo tiene por objeto analizar y exponer las pautas y criterios necesarios para determinar de qué estamos hablando cuando hacemos alusión al concepto «información pública» a los efectos del régimen regulador, estatal y catalán, del derecho de las personas a acceder a información pública.

El derecho de acceso a la información pública cuenta con un explícito reconocimiento constitucional en el artículo 105 b) de la Constitución española (CE), en tanto que prescribe un mandato al legislador en aras a regular «el acceso de los ciudadanos a los archivos y registros administrativos, salvo en lo que afecte a la seguridad y defensa del Estado, la averiguación de los delitos y la intimidad de las personas.» La ubicación sistemática del precepto constitucional, en la parte orgánica de la CE -dentro del Título IV relativo al Gobierno y la Administración-, y no en la parte dogmática -en la Sección 1a, Capítol II, del Título I CE (art. 14 a 29 y 30.2)-, determina su configuración legal, sin que se beneficie por tanto de las garantías propias de los derechos de naturaleza fundamental -se regula mediante ley ordinaria y no es susceptible de amparo constitucional, entre otras consecuencias, de acuerdo con lo dispuesto en el artículo 53.2 de la CE-.

Pese a ello, una parte de la doctrina ${ }^{2}$ ha llegado al consenso jurídico sobre la naturaleza iusfundamental del derecho de acceso a la información pública, bien como derecho autónomo, o bien de acuerdo con la mayorías de autores que defienden esta naturaleza, como derecho integrante del derecho a la libertad de expresión y de información (artículo $20 \mathrm{CE}$ ), en consonancia con los tratados internacionales y el derecho comunitario ${ }^{3}$, así como de acuerdo con la doctrina jurisprudencial más reciente del Tribunal Europeo de Derechos Humanos ${ }^{4}$.

En virtud del mandato constitucional referido, el artículo 37 de la Ley 30/1992, de 26 de noviembre, de Régimen Jurídico de las Administraciones Públicas y del Procedimiento Administrativo Común (Ley 30/1992) ofrecia una regulación incompleta y sumamente condicionada del derecho a acceder a información pública, a día de hoy derogada: primeramente, porque el precepto se ubicaba a modo de un contenido más de la ley reguladora del régimen administrativo general, y no como una ley específica y horizontal en materia de transparencia; en segundo lugar, porque su apartado sexto se remitía al régimen establecido en

\footnotetext{
${ }^{2}$ En este sentido, véanse Guichot Reina, E. 2011. Transparencia y acceso a la información pública en España: análisis y propuestas legislativas, Madrid: Fundación Alternativas (Documento de trabajo 170/2011); Hernández Godínez, A. 2010. El acceso a la información pública. Evolución y consolidación de un derecho fundamental de nueva generación, Madrid: Universidad Carlos III (tesis doctoral); y Sánchez de Diego Fernández de la Riva, M. 2008. «Un derecho fundamental a acceder a la información pública», El derecho de acceso a la información pública, 7-41.

${ }^{3}$ Artículo 10.2 del Convenio Europeo de Derechos Humanos; artículo 19 de la Declaración Universal de los Derechos Humanos; artículo 42 de la Carta de los Derechos Fundamentales de la Unión Europea; artículo 15 del Tratado de Funcionamiento de la Unión Europea, entre otros.

${ }^{4}$ Caso Társaság a Szabadságjogokért, sentencia de 14 de abril de 2009, y Caso Kennedy, sentencia de 16 de agosto de 2009
} 


\section{Oliver García Muñoz}

disposiciones especificas y, en lugar de constituir una ley básica de mínimos, parecía configurarse como una ley general que podía ser desvirtuada por cualquier norma sectorial; y en cuanto al ejercicio del derecho de acceso se refiere, se encontraba sujeto a condiciones significativamente limitativas: era necesario que la información estuviese integrada en un documento y éste, a su vez, en un expediente, es decir, se refiriese a un procedimiento administrativo; a la vez, había de tratase de un procedimiento cerrado o terminado, y la información debía encontrase en un archivo o registro administrativo. La redacción del precepto, además, parecía exigir, en la persona solicitante, la concurrencia de un interés legítimo para acceder a la información.

Esta limitativa regulación inicial del derecho de acceso ha sido reemplazada por las actualmente vigentes leyes de transparencia, que vienen a reconocer un derecho subjetivo de cualquier person $a^{5}$ de carácter universal, en el sentido que puede ser ejercido tanto por personas interesadas en un procedimiento administrativo como aquellas otras que no sean titulares de ningún interés o derecho que pueda motivar la solicitud de acceso; y, a su vez el derecho puede tener por objeto tanto la información pública integrada en un procedimiento abierto o en trámite, así como la que forma parte de un procedimiento concluido o terminado, o incluso la no integrada en ningún procedimiento determinado, y todo ello con independencia de que la información se encuentre o no en un archivo o registro.

En este sentido, la Ley estatal básica 19/2013, del 9 de diciembre, de transparencia, acceso a la información pública y buen gobierno (Ley 19/2013) define en su artículo 13 el concepto de «información pública» como «los contenidos o documentos, cualquiera que sea su formato o soporte, que obren en poder de alguno de los sujetos incluidos en el ámbito de aplicación de este título y que hayan sido elaborados o adquiridos en el ejercicio de sus funciones.»

Según su disposición final octava, la Ley 19/2013 se dicta al amparo de los artículos 149.1.1 $1^{\mathrm{a}}, 149.1 .13^{\mathrm{a}}$ y $149.1 .18^{\mathrm{a}}$ de la CE, que son considerados "títulos competenciales horizontales" en relación, respectivamente, con «la regulación de las condiciones básicas que garanticen la igualdad de todos los españoles en el ejercicio de los derechos y en el cumplimiento de los deberes constitucionales»; las «bases y coordinación de la planificación general de la actividad económica»; y las «bases del régimen jurídico de las Administraciones públicas (...y) el procedimiento administrativo común, sin perjuicio de las especialidades derivadas de la organización propia de las Comunidades Autónomas; (...)». Según Velasco ${ }^{6}$, «si bien el artículo $149.1 .18^{a}$ de la CE es el que mejor ampara la regulación del procedimiento relativo al derecho de acceso a la información pública y las

\footnotetext{
${ }^{5}$ En el caso de la Ley 19/2014 del Parlamento de Cataluña, de 29 de diciembre, de transparencia, acceso a información pública y buen gobierno, el articulo 18.3 exige, para el ejercicio del derecho por una persona física, que ésta tenga 16 años.

6 Velasco Rico, C. I. 2013. «Análisis en clave competencial del Proyecto de Ley estatal sobre Transparencia, Acceso a la Información Pública y Buen Gobierno», Revista d'Estudis Autonómics $i$ Federals, 17: 279-328 (p. 320).
} 


\section{El concepło de información pública ...}

obligaciones establecidas en materia de publicidad activa y transparencia, la invocación de los artículos $149.11^{\mathrm{a}}$ y $149.1 .13^{\mathrm{a}}$ de la CE nos parece poco acertada puesto que ni estamos en presencia de un derecho constitucional de las secciones $1^{\text {a }}$ y $2^{\text {a }}$ del capítulo II, del título I de la Constitución, ni el proyecto regula actividad económica alguna.»

En cualquier caso, los títulos competenciales citados fundamentan en la regulación del derecho de acceso a información pública una indiscutible competencia compartida entre la ley básica estatal y las normas legales autonómicas que se han aprobado o se aprueben en el futuro en relación con esta materia en desarrollo de la Ley 19/2013, con el fin de adaptarla a las peculiaridades organizativas de cada Comunidad autónoma sobre la base de las competencias en materia de procedimiento administrativo, autoorganización y, sectorialmente, por ejemplo, en materia de archivos, que estas han asumido en sus respectivos Estatutos. En cualquier caso, Velasco afirma al respecto que «la norma estatal debe ser tenida por un mínimo común, mejorable por las regulaciones autonómicas. (...) En cuanto a la regulación del procedimiento de ejercicio del derecho de acceso podría pensarse, por ejemplo, en una reducción de los plazos máximos de resolución previstos en la norma estatal. En este supuesto se trata, sobre todo, de la ampliación o regulación más favorable por parte de la normativa autonómica del derecho subjetivo de acceso a la información pública reconocido a todas las personas. El principio de igualdad no será menoscabado, en tanto que la igualación de los ciudadanos ante todas las administraciones públicas se garantizará por las disposiciones de la norma estatal. El hecho de que determinadas (Comunidades autónomas) decidan mejorar la situación del ciudadano en esta materia, regulando de forma más favorable el ejercicio de dicho derecho, pero respetando los límites fijados por el Estado, no atenta contra la igualdad en cuanto al ejercicio del derecho de acceso. De lo que se trata es de establecer regulaciones que favorezcan el ejercicio pleno y expansivo de los derechos en beneficio de los ciudadanos individualmente considerados y de la sociedad en su conjunto. Por ello, las normas autonómicas no supondrian peligro alguno, al contrario.»

Por su parte, el artículo 159 del Estatuto de Autonomía de Cataluña (EAC), que regula la competencia de la Generalitat en materia de régimen jurídico, procedimiento, contratación y responsabilidad en las administraciones públicas catalanas, dispone que «corresponde a la Generalitat, en materia de régimen jurídico y procedimiento de las administraciones públicas catalanas, la competencia exclusiva en lo no afectado por el artículo $149 \cdot 1.18^{a}$ de la Constitución.»

En virtud de dicha competencia, el Parlamento de la Generalitat de Cataluña aprobó la Ley 26/2010, del 3 de agosto, de régimen jurídico y de procedimiento de las administraciones públicas catalanas, y más recientemente, y por lo que aquí interesa, la Ley 19/2014, de 29 de diciembre, de transparencia, acceso a la información pública y buen gobierno (Ley 19/2014), cuyo artículo 2.b) define como 


\section{Oliver García Muñoz}

«información pública», a los efectos de la aplicación de sus previsiones, «la información elaborada por la Administración y la que ésta tiene en su poder como consecuencia de su actividad o del ejercicio de sus funciones, incluida la que le suministran los otros sujetos obligados -por la citada ley-.»

Las definiciones de «información pública» que manejan tanto la ley estatal como la catalana van pues en la línea del Convenio del Consejo de Europa n 205 sobre el acceso a los documentos públicos (Convenio CE 205) -cuyo artículo 1.2 b) se refiere a «toda la información registrada (archivada) de cualquier forma, elaborada o recibida, y en posesión de las autoridades públicas»-.

Igualmente el Reglamento (CE) n’ 1049/2001 relativo al acceso del público a los documentos del Parlamento Europeo, del Consejo y de la Comisión (Reglamento 1049/2001) se refiere, en su artículo 2.3, a «todos los documentos que se encuentren en poder de una institución; es decir, los documentos por ella elaborados o recibidos y que estén en su posesión, en todos los ámbitos de actividad de la Unión Europea.»

De acuerdo con el Informe de la Comisión europea, de 30 de enero de 2004, sobre la aplicación de los principios del Reglamento 1049/2001, en la letra a) del artículo 3 del Reglamento figura en realidad «una definición muy amplia del concepto de "documento". Por tanto, según el Reglamento, se entenderá por "documento" todo contenido, sea cual fuere su soporte.» En este sentido, el Tribunal de Primera Instancia y el Tribunal de Justicia basan el principio del acceso parcial en la interpretación del derecho de acceso a los documentos como un derecho de acceso a los elementos de información que contienen; en tanto algunos de estos elementos no estén cubiertos por una excepción al derecho de acceso, deberán divulgarse.

En cualquier caso, y en aras a poder concretar la interpretación del concepto «información pública» al que se refieren tanto la ley básica estatal como la ley aprobada por el Parlamento de la Generalitat de Cataluña, al regular el derecho de acceso a la información pública, resulta imprescindible tener en cuenta y analizar la doctrina que al respecto han venido asentando los órganos de garantía del derecho de acceso a la información pública. Me refiero al Consejo de Transparencia y Buen Gobierno (CTBG) y a la Comisión de Garantía del derecho a la información pública (GAIP).

El CTBG fue creado en el artículo 33 de la Ley 19/2013 como organismo público de la Administración General del Estado, adscrito al Ministerio de Hacienda y Administraciones Públicas, con la finalidad de promover la transparencia de la actividad pública, velar por el cumplimiento de las obligaciones de publicidad, salvaguardar el ejercicio de derecho de acceso a la información pública y garantizar la observancia de las disposiciones de buen gobierno. Ante el CTBG, cuyo estatuto fue aprobado por Real Decreto 919/2014, de 31 de octubre, puede interponerse una reclamación frente a toda resolución expresa o presunta en 


\section{El concepto de información pública ...}

materia de acceso a información pública, con carácter potestativo y previo a su impugnación en vía contencioso-administrativa, de acuerdo con lo previsto en el artículo 24 de la Ley 19/2013.

De acuerdo con la disposición adicional cuarta de la citada ley, la resolución de la reclamación prevista en su artículo 24 corresponderá, en los supuestos de resoluciones dictadas por las Administraciones de las Comunidades Autónomas y su sector público, y por las Entidades Locales comprendidas en su ámbito territorial, al órgano independiente que determinen las Comunidades Autónomas, aunque las mismas podrán atribuir la competencia para la resolución de la reclamación al CTBG mediante el correspondiente convenio con la Administración General del Estado.

La Comunidad autónoma de Cataluña cuenta con un órgano colegiado independiente propio, la GAIP, prevista en el artículo 39 y siguientes de la Ley 19/2014 y cuyo reglamento fue aprobado por Decreto 111/2017, de 18 de julio. A la GAIP, adscrita al departamento de la Administración de la Generalitat competente en materia de políticas de transparencia, se le encomienda la función de velar por el cumplimiento y las garantías del derecho de acceso a la información pública en las administraciones catalanas (artículo 3 de su reglamento); en especial, es la competente para resolver la reclamación gratuita y voluntaria contra las resoluciones expresas o presuntas en materia de acceso a la información pública y contra las que resuelvan el recurso de reposición contra las mismas.

\section{2. ÁMBITO OBJETIVO DEL CONCEPTO.}

\subsection{Información y documentos: distinción.}

El concepto de «información», a los efectos del objeto del derecho de acceso regulado en las leyes de transparencia, es mucho más amplio que el de documento, ya que incluye también datos o conocimientos no plasmados documentalmente (datos documentados) es decir, de obtención directa porque se encuentran recogidos en un soporte material concreto -concepto de «documento» en sentido estricto-, sino también los datos existentes pero dispersos, o lo que es lo mismo, que no se encuentran materializados en un soporte concreto y fácilmente identificable - v. gr., en bases de datos, en un registro informático, o referentes a hechos o a situaciones fácticas conocidas por la Administración, todavía pendiente de elaborar formalmente-.

Existen diferentes definiciones que encajan y describen con amplitud el concepto de información que se identifica con el objeto del derecho de acceso regulado en las leyes de transparencia. En este sentido, el Diccionario de la Real Academia Española de la Lengua define la información como la comunicación o adquisición de conocimientos que permiten ampliar o precisar los que se poseen sobre una determinada materia. La noción de información, pues, mucho más allá de la mera obtención de datos aislados desprovistos de valor per se, implica un mensaje con 


\section{Oliver García Muñoz}

sentido que permite a su destinatario -haciendo valer su inteligencia y experiencia previas- adoptar decisiones con conocimiento de causa, de tal forma que comporta una comunicación o adquisición de conocimientos con el fin de ampliar o precisar los que ya se poseen sobre una determinada materia.

En nuestro ordenamiento jurídico, cabe destacar al respecto el apartado primero del artículo 49 la Ley 16/1985, de 25 de junio, del patrimonio histórico español (LPH), que a los efectos de esta Ley hace alusión a «toda expresión en lenguaje natural o convencional y cualquier otra expresión gráfica, sonora o en imagen, recogidas en cualquier tipo de soporte material, incluso los soportes informáticos.». En un similar sentido la Ley 9/1993, de 30 de septiembre, del patrimonio cultural catalán, en el artículo 19, viene a ofrecer también, en realidad, una completa noción del concepto de «información», que abarca «toda expresión en lenguaje oral, escrito, de imágenes o de sonidos, natural o codificado, recogida en cualquier tipo de soporte material, y cualquier otra expresión gráfica que constituya un testigo de las funciones y las actividades sociales del hombre y de los grupos humanos, con exclusión de las obras de investigación o de creación».

En esta línea la doctrina de la GAIP ha reconocido en numerosas ocasiones que «el derecho de acceso (...) no se puede limitar ni condicionar a los documentos preexistentes» (Resolución de la GAIP de la Reclamación 15/2016), de tal forma que comprende, además de la documentación, también otros «datos o el conocimiento que tiene la Administración -en su poder-, de ámbitos que son de su competencia», cualquiera que sea su formato o soporte (Resolución de la GAIP 151/2018). Por su parte, en la Resolución de la Reclamación 36/2015 la GAIP afirma que "en contraposición con el antecedente de la (Ley 30/1992), (la Ley 19/2014) garantiza el derecho de acceso a la información pública, no sólo en los documentos públicos, (... de tal forma que) no se pueden excluir solicitudes de información que trasciendan uno o unos determinados documentos".

La concepción amplia del concepto de datos del cual debemos partir nos obliga a admitir que, aunque ciertamente los datos alfanuméricos o digitales que forman parte de un fichero o de una base de datos constituyen «las expresiones más típicas de lo que es información» (Resolución de la GAIP 299/2017), los datos pueden adoptar múltiples expresiones o tipologías de conocimiento: desde fórmulas, procedimientos de cálculo o algoritmos matemáticos - Resolución de la GAIP de la Reclamación 123/2016-, hasta objetos materiales y muestras de productos que sirven para proporcionar o acreditar conocimiento, por ejemplo, en un procedimiento de contratación (Resolución de la GAIP 329/2017).

Cuando el artículo 13 de la Ley 19/2013, al definir qué se entiende por información pública hace referencia a «contenidos o documentos, cualquiera que sea su formato o soporte»; parece que el término «contenidos» es introducido en la definición por el legislador para albergar otros objetos distintos al documento, aunque «contenidos» y «documentos» no aluden de hecho a realidades 


\section{El concepło de información pública ...}

homogéneas: mientras que los documentos se refieren al soporte de la información, los «contenidos» se refieren a la información misma. Si partimos del concepto de documento que se da en nuestro ordenamiento -soporte que incorpora una información -, tendremos que aceptar que no existe espacio fuera del concepto, pues abarca cualesquiera posibles objetos que contengan una información $y$, entonces, el término «contenidos» poco o nada aportaría a la definición de información, lo que no parece lógico. Barrero ${ }^{7}$ sostiene al respecto que «es posible que estos contenidos (...) no sean más que aquellos otros objetos que aportan una información a la que, a diferencia del documento, no es posible acceder sin su previo tratamiento por los sujetos obligados a facilitarla», o dicho de otra manera, «puede entenderse que el precepto reconoce un derecho de acceso tanto a la información accesible en el momento en el que se formula la solicitud («información disponible»), como también a la información necesitada de un tratamiento de los datos con la finalidad de hacer posible el ejercicio del derecho». Esta interpretación se aviene con la obligación impuesta a los sujetos obligados de realizar las actuaciones necesarias para que la información esté disponible y accesible.

La Ley catalana 19/2014, en cambio, da un paso más e incluso elude cualquier referencia a los documentos a la hora de definir qué es información pública, que no tiene por qué encontrarse recogida en un documento.

\subsection{Prexistencia de los datos y necesidad de una mínima elaboración previa de la información.}

Un primer presupuesto a analizar en la admisión de las solicitudes de acceso consiste en la necesidad de que la información solicitada exista previa y efectivamente en el momento de la presentación de la solicitud (Resoluciones de la GAIP 94/2017, 109/2017, o 150/2017).

Esta premisa, sobre la preexistencia de los datos, permite afirmar que en ningún caso podemos hablar de información pública cuando su obtención implica la necesidad de «elaborar» o generar propiamente los datos solicitados, cuando son inexistentes en la esfera de control de la Administración responsable ${ }^{8}$.

En su dictamen 6/2016 la GAIP recuerda en este sentido que es información pública «toda la que la Administración tiene efectivamente (y actualmente) en sus manos», de lo cual cabe extraer que el derecho de acceso puede ser ejercido en

\footnotetext{
7 Barredo, C., Descalzo, A., Guichot, E., Hogué, C., Palomar, A. 2014, Transparencia, Acceso a la Información Pública y Buen Gobierno. Estudio de la Ley 19/2013, de 9 de diciembre. Madrid: Tecnos (p. 204).

${ }^{8}$ Es el caso, por ejemplo, de los datos relativos al porcentaje de alumnos de determinados centros docentes que han querido continuar los estudios después de concluir el ciclo medio, información que la Administración requerida parece no tener y que, por tanto, no puede ser objeto del derecho de acceso (Resolución de la GAIP de la Reclamación 68/2016), o de la solicitud de acceso a actas de reuniones e informes justificativos inexistentes, motivo por el cual el derecho de acceso tendrá que ser considerado satisfecho mediante una respuesta escrita por la que se deje constancia fehacientemente de su inexistencia (Resolución de la GAIP de la Reclamación 142/2016).
} 


\section{Oliver García Muñoz}

relación con toda la información que materialmente se encuentre en manos de la Administración afectada, con independencia de la fecha o momento en el cual fue elaborada y de los eventuales referentes temporales que puedan haber en su contenido.

Testigo de este presupuesto, relativo a la prexistencia de la información solicitada, es la causa de inadmisión que explícitamente recoge la letra a) del apartado primero del artículo 18 de la Ley 19/2013, según el cual, se inadmitirán a trámite, mediante resolución motivada, las solicitudes «que se refieran a información que esté en curso de elaboración o de publicación general». De acuerdo con la doctrina del CTBG, dicha causa de inadmisión debe entenderse relacionada con el hecho de que la información está elaborándose o cuya publicación general está siendo preparada, y lo que está implícito en esta causa de inadmisión es que, o bien la información aún no está elaborada, por lo que no se incluye en el propio concepto de información pública del artículo 13 de la Ley 19/2013, o bien la misma va a ser publicada de tal manera, que, en un plazo de tiempo razonable, pueda ser accesible con carácter general (Resoluciones del CTBG R/0583/2018 y $\mathrm{R} / 0202 / 2016$ ).

Ahora bien, sentado lo anterior, hay que admitir que con frecuencia puede no resultar fácil identificar o recoger datos cuya obtención es indirecta, en el sentido que requiera asumir, los sujetos obligados, cierta tarea previa de búsqueda, recopilación, sistematización, refundición, deducción o mínimo análisis con la finalidad de poder dar satisfacción al derecho de las personas a su acceso.

Podemos afirmar pues que el ejercicio legítimo del derecho de acceso a los datos públicos admite, e incluso exige, en muchos casos, un desarrollo indiscutible de trabajos de elaboración previa de la información en el sentido de tener que llevar a cabo alguna de las acciones mencionadas.

En este sentido se ha pronunciado en diferentes ocasiones el CTBG. En su criterio 7/2015 ha sostenido que «la información tiene que comprender necesariamente un mínimo de elaboración a partir de los datos y documentos existentes (...)», lo cual puede requerir la «mera agregación, o suma de datos, o el mínimo tratamiento de los mismos».

De forma similar la GAIP impone a las Administraciones el deber de buscar exhaustivamente la información solicitada entre sus archivos (Resolución de la GAIP de la Reclamación 28/2015) y de llevar a cabo cierta tarea de elaboración de los datos accesibles (Resolución de la GAIP de la Reclamación 36/2015). Explicitamente en su dictamen 6/2016 la GAIP afirma que en los casos en los que la información solicitada no es identificable con documentos determinados, su obtención requiere una tarea de elaboración por parte de la Administración y, por lo tanto, «la necesidad de elaborar información expresamente para atender solicitudes de acceso es una eventualidad que deriva en pura lógica del hecho de que este derecho se proclame legalmente en relación con la información pública 


\section{El concepto de información pública ...}

(...)». De ello se desprende necesariamente que el hecho de que la solicitud de acceso tenga por objeto información que se tenga que construir de manera completa a partir de información dispersa que hasta ahora la norma no obligaba a disponer de manera estructurada, no puede ser, por sí solo, un motivo de inadmisibilidad.

En este mismo sentido, y tal y como ilustra la doctrina del CTBG, no puede ser inadmitida a trámite la solicitud de datos respecto a los que el método de archivos utilizado no permita la localización directa e inmediata de la documentación, o se acredite la ausencia de ficheros de datos conjuntos y homogéneos y, por el contrario, su acceso requiera realizar una simple tarea de recopilación, en el sentido de tener que acudir a varias fuentes y unidades internas de información bajo el control de la unidad administrativa requerida? .

Así lo expresa abiertamente el artículo $37 \mathrm{~g}$ ) de la Ley Foral de Navarra 5/2018, del 17 de mayo, de Transparencia, acceso a la información pública y buen gobierno, que obliga a admitir las solicitudes de acceso que comporten una «acción que requiera aglutinar la información dispersa en varios documentos existentes».

El deber de dar trámite a las solicitudes de acceso que precisan de una «simplicidad de tratamiento» de los datos solicitados, o de una «mera recopilación de información existente», cuando «no haga falta un trabajo específico ${ }^{10}$ al efecto, ha sido reconocido también en sede jurisdiccional, precisamente en un caso de ejercicio del derecho de acceso que ha llegado al Tribunal Supremo (TS) Sentencia TS de 16 de octubre de 2017, n 1547/2017, Sección $3^{\text {a }}$ - y en el cual, por silencio administrativo, la Corporación de Radio Televisión Española (RTVE) había negado a la persona solicitante tener acceso a información sobre los gastos que supuso la participación en el festival de Eurovisión del año 2015: «la información que se solicita tiene que encontrarse en los documentos contables y presupuestarios de la entidad, y no se aprecia (...) un tratamiento previo de la información con el fin de obtener algo diferente de lo que se dispone, más allá de constatar las diferentes partidas en que se contengan los datos de los gastos» interesados.

\subsection{Límites al deber previo de elaborar la información.}

Ahora bien, el deber de las Administraciones de buscar o recopilar la información solicitada no puede ser en ningún caso de exigencia ilimitada, y por este motivo el legislador se ha encargado de excepcionar expresamente el derecho de acceso en

\footnotetext{
${ }^{9}$ Véanse, entre otras, las resoluciones del CTBG: R/O495/2017 -acceso a copias de facturas de gastos públicos en combustible-; R/0536/2017 -entrega de estudios e informes de la entidad de ingeniería "INECO"-; R/0325/2018 -identificación de agentes del Cuerpo Nacional de Policía suspendidos por faltas leves-; o R/0520/2018 - contratos suscritos entre una empresa y RTVE-

${ }^{10}$ Fernández Salmerón, M. y Sierra Rodríguez, J. 2019. «Inadmisión y necesidad de reelaboración ante el derecho de acceso a la información pública», Revista de Estudios de la Administración local y autonómica, 11: 56-74 (p. 70).
} 


\section{Oliver García Muñoz}

los casos en los cuales la obtención de información se convierte en una carga excesivamente gravosa para la Administración responsable.

En este sentido, el artículo 18.1 de la Ley 19/2013, en su letra c), prescribe la inadmisión a trámite de las solicitudes de acceso cuando se refieran a «información para cuya divulgación sea necesaria una acción previa de reelaboración».

En un sentido similar, aunque no equivalente, la letra b) del apartado $1^{\circ}$ del artículo 29 de la Ley 19/2014 permite eludir la tramitación de la solicitud de acceso, y evitar entrar en el fondo, en los supuestos en los que la obtención de la información solicitada requiere de «una tarea compleja de elaboración o reelaboración». El tenor literal de este supuesto ya deja entrever que este motivo de inadmisión en la ley catalana resulta más restrictivo, y por ende, más favorable al derecho de acceso, pues requiere una nota de "complejidad" que no exige la ley básica estatal.

Pero, por otro lado, la Ley 19/2014, prevé además, en el apartado segundo del citado artículo 29, otra causa de inadmisión directamente relacionada con la elaboración de información, según la cual, «son inadmitidas a trámite las solicitudes de información consistentes en consultas jurídicas o peticiones de informes o dictámenes".

Estos supuestos de inadmisión van en la línea del Informe de la Comisión europea, de 30 de enero de 2004, sobre la aplicación de los principios del Reglamento 1049/2001, cuando afirma que dicho Reglamento «no obliga en ningún caso a las instituciones a crear documentos con el fin de responder a una solicitud. Cuando la información solicitada no está disponible en uno o más documentos existentes, sino que implica realizar investigaciones en fuentes distintas y la elaboración de documentos específicos y/o la agregación de datos, la solicitud sobrepasa claramente el ámbito de aplicación del Reglamento.»

Sin embargo, ¿cómo debemos interpretar el alcance de sendas causas de inadmisión? ¿Qué significa a estos efectos una «acción previa de reelaboración»? ¿Qué debemos entender a estos efectos por «complejidad» en la elaboración y reelaboración de datos? Dicho de otra manera, ¿en qué casos la búsqueda, la recopilación o la obtención de los datos solicitados constituye una tarea ardua o compleja que legitima a la Administración pública a dejar de atender la solicitud de acceso? ¿Dónde está el límite entre lo admisible (el mínimo de elaboración o tratamiento a partir de los datos y documentos existentes, o la mera agregación o suma de datos) y lo inadmisible (necesidad de una «acción previa de reelaboración» o de una elaboración o reelaboración «complejas»)?

La respuesta no es fácil; hay que buscarla en cada caso concreto, y de manera suficientemente justificada.

Ciertamente acostumbra a ser determinante, a los efectos de apreciar esta causa de inadmisión, la necesidad material de tener que extraer la información de un 


\section{El concepto de información pública ...}

elevado número o diversidad de fuentes de información -de excesivos documentos, de ingentes expedientes, de voluminosas bases de datos, o de una multiplicidad de archivos de procedencia-.

Sin embargo, no hay suficiente con eso: el CTBG ha venido a admitir que «la información voluminosa no origina inadmisión» (criterio 7/2015, o resoluciones R/0495/2017 y R/0198/2018). En un similar sentido la GAIP ha reconocido expresamente que la implicación en el acceso de un volumen de expedientes ciertamente elevado no sería per se excluyente de la tramitación (Resolución de la GAIP 388/2017).

Y con el objeto de facilitar un argumento al respecto, teniendo en cuenta la ausencia de parámetros normativos, han sido estos órganos de garantía del derecho de acceso los que, a lo largo de su doctrina, se han encargado de establecer algunos criterios que pueden servir para orientar a los sujetos obligados en la identificación de casos en los que la elaboración de la información puede justificar o fundamentar una inadmisión de la solicitud de acceso.

En aras a interpretar el alcance de la «acción previa de reelaboración» a que alude el artículo 18.1 de la Ley 19/2013, en su letra c), en varias ocasiones el CTBG ha equiparado la tarea de «reelaboración» a la necesidad de tener que confeccionar expresamente un documento especifico o informe a medida ad hoc para dar respuesta a una solicitud de acceso ${ }^{11}$.

Hay que decir que esta interpretación casa más bien con el motivo de inadmisión que la Ley 19/2014 recoge en el apartado segundo de su artículo 29 -«consultas jurídicas o peticiones de informes o dictámenes»-, causa de inadmisión que, en cambio, no ha sido prevista de forma expresa por el legislador estatal. Varias resoluciones de la GAIP han concretado la aplicabilidad de dicha causa de inadmisión a aquellas solicitudes por las que se pide una motivación o una justificación de determinadas situaciones o decisiones administrativas. En este sentido, en la Resolución de la GAIP de la Reclamación 172/2016, en un caso en que se solicita una exposición de los errores cometidos en un examen, la GAIP concluye que es procedente estimar la solicitud en caso que exista un documento previo en el que consten los errores aludidos, y siempre que no concurra ningún limite legal oponible al acceso. Pero «en caso que dicho documento no exista, y fuese necesario redactarlo expresamente a los efectos de atender la solicitud, entonces esta tarea no se incluye dentro de lo que garantiza el derecho de acceso a la información pública».

\footnotetext{
${ }^{11}$ Véanse, entre otras, las resoluciones del CTBG R/0111/2018 -fecha de nacimiento de funcionarios destinados al exterior-; R/0343/2018 -información, no sobre el número, sino relacionada con la razón de archivo de sanciones en materia de seguridad ciudadana-; R/0374/2017 - número de plazas para reclusos a cada uno de los centros penitenciarios-; R/0444/2018 - información sobre las incidencias en el servicio de Renfe Cercanías en Asturias-: o R/0490/2017 - informaciones sobre denuncias en el buzón de lucha contra el fraude electoral-.
} 


\section{Oliver García Muñoz}

En cuanto a la formulación por la norma legal catalana de la causa de inadmisión consistente en la necesidad de tener que llevar a cabo «una tarea compleja de elaboración o reelaboración» para satisfacer la solicitud de acceso (artículo 29.1 b), la GAIP (Resolución de la GAIP de la Reclamación 5/2015, Resolución de la GAIP de la Reclamación 36/2015, o Resoluciones de la GAIP 388/2017 y 102/2018, entre otras) se ha encargado de asentar criterios para determinar la nota de «complejidad» en las tareas de elaboración o reelaboración que requiere la estimación de la causa de inadmisión prevista: «para determinar el alcance de este concepto hace falta tener en cuenta el contexto de la realidad de los instrumentos, medios y recursos de almacenaje, gestión documental y tratamiento de la información pública en las administraciones contemporáneas, caracterizada por la coexistencia de formatos digitales e impresos en el archivo de los documentos públicos y por el mantenimiento de grandes volúmenes de información en archivos en papel».

En efecto, resulta necesaria la concurrencia de alguno de los indicios fácticos que, en intima relación con cuestiones eminentemente pragmáticas como son la organización administrativa, los recursos públicos o la gestión de la información, supongan una verdadera traba o impedimento material de especial consideración en la elaboración de los datos. En este contexto, de acuerdo con la doctrina de la GAIP citada en el párrafo anterior, pueden ser indicios de una tarea compleja de elaboración o reelaboración los supuestos en los cuales se acredite que la obtención de los datos solicitados requiere una extracción indirecta de documentos que tienen un contenido más amplio, especialmente si esta tarea (i) comporta utilizar medios técnicos precisos para la obtención de los datos que no se disponen, como pueden ser programas informáticos especializados o fuera del uso común o habitual de la Administración; (ii) tenga que llevarse a cabo una tarea de recopilación u obtención manual; (iii) deba realizarse una actividad de análisis o de interpretación de datos; (iv) haya que tener en cuenta una combinación de diferentes formatos de los datos existentes, electrónicos y en papel; o ( $v$ ) exista una lejanía física o temporal de la información dispersa -documentos en diferentes expedientes o archivos, o referentes a un lapso de tiempo muy amplio-, entre otras circunstancias.

Este listado de indicadores no consiste pues en un numerus clausus, sino que, por el contrario, admite cualquier elemento material revelador de que la tarea de búsqueda y obtención de la información no es sencilla.

En cualquier caso deben acreditarse suficientemente dichas circunstancias, de tal manera que cuanto mayor sea su concurrencia conjunta y/o su intensidad, mayor peso y razón de ser tendrá la consideración de la complejidad como causa de inadmisión de la solicitud. Y a los efectos de la acreditación, será conveniente que la Administración justifique debidamente la indisposición de los recursos suficientes, humanos o materiales, necesarios para la obtención o la extracción de los datos solicitados, de tal forma que pueda preverse razonablemente un 


\section{El concepto de información pública ...}

incumplimiento del plazo legal máximo prorrogado para resolver y notificar la resolución de la solicitud de acceso.

En este mismo sentido, en su criterio 7/2015 el CTBG interpreta que existe una «acción previa de reelaboración» que justifica la inadmisión en los casos en que, entre otros motivos, no se dispongan «de los medios técnicos necesarios para extraer y explotar la información concreta que se solicita, resultando imposible proporcionar la información solicitada».

No obstante, conviene tener presente que el régimen de acceso a la información pública no permite oponer al ejercicio de este derecho circunstancias propias de la organización interna de la Administración, como puedan ser la renovación del personal o una gestión indebida de sus archivos, circunstancias éstas que podrían justificar, como mucho, una ampliación del plazo de resolución previsto -en el artículo 20.1 de la Ley 19/2013 y en el artículo 33.2 de la Ley 19/2014- (Resolución de la GAIP de la Reclamación 28/2015).

En la Resolución 78/2017, la GAIP resuelve la inadmisión, por complejidad en la elaboración, del acceso a una copia de la totalidad de los expedientes administrativos de adjudicación de concursos públicos celebrados entre 2011 y 2015 en una entidad pública, con fundamento en la concurrencia de varios factores condicionantes: el volumen ingente de la documentación implicada -resultan afectados 801 expedientes, representativos de más de un kilómetro y medio documentos, lo cual supone más de 16 millones de folios-, la diversidad de tipología de documentos contenedores de cada expediente, y la falta de digitalización de muchos de ellos, lo cual comporta una tarea de localización manual, así como el consecuente deber de digitalizarlos. Del conjunto de estas circunstancias hay que inferir la disposición de recursos personales limitados, en tal medida que atender la solicitud de acceso podria afectar seriamente al normal funcionamiento de la entidad.

También en la Resolución 336/2017 la GAIP concluye, por el mismo motivo, la improcedencia de dar trámite a una solicitud de acceso al importe de las sanciones impuestas a raíz de varios expedientes sancionadores, dado no sólo el elevado volumen de expedientes -más de 40.000-, sino también el amplio periodo de tiempo en que se comprenden -10 años-, la necesidad de extracción manual de muchos de los datos por falta de informatización, o el hecho de que los procedimientos objeto de acceso fueron incoados en varios departamentos y gestionados mediante distintas aplicaciones. La consideración global de todas estas circunstancias conlleva considerar la necesidad de desarrollar una «recopilación laboriosa» de información, lo que supondría una carga adicional de trabajo desproporcionado.

La complejidad en la elaboración de la información solicitada, dispersa en todos departamentos de la Administración de la Generalitat, así como en su 


\section{Oliver García Muñoz}

anonimización -en la medida en que se contienen datos personales relativos a valoraciones de candidatos no seleccionados- sirve también de fundamento a la GAIP para apreciar inadmisión parcial la solicitud de acceso, cuyo objeto se refería a toda la documentación contenida en procedimientos de selección y provisión publicados en el portal del empleado público de la Generalitat de Cataluña (ATRI): se estima el acceso sólo a los informes de motivación del uso urgente del sistema extraordinario de provisión y a las resoluciones de nombramiento (Resolución de la GAIP 102/2018).

Por el contrario, la GAIP no ha entendido justificada la concurrencia de complejidad en la elaboración de la información como causa de inadmisión de las solicitudes de acceso que se refieren a un escaso número de expedientes (Resolución de la GAIP 2/2017 - información retributiva de un total de menos de 50 cargos directivos, relativa a los 10 años anteriores; Resolución de la GAIP 153/2017 - 169 sanciones impuestas en materia de tráfico y cantidades efectivamente recaudadas entre los años 2009 y 2016; o Resolución de la GAIP 196/2017 -se solicita información que implica obtener una sola cifra por año, en relación con la recaudación en concepto de liquidaciones presupuestarias de un determinado tributo, los 21 años anteriores); tampoco la lejanía física del depósito o ubicación de los datos en ningún caso puede ser, por si sola, motivo de inadmisión (Resolución de la GAIP de la Reclamación 68/2016 - información sobre el porcentaje de aprobados y media de notas obtenidas en diferentes centros educativos), entre otros ejemplos.

Con todo, no puede negarse la indeterminación inherente de los términos con los que las citadas leyes de transparencia definen esta causa de inadmisión («tarea compleja de elaboración o reelaboración» en la Ley 19/2014, o «acción previa de reelaboración» en la Ley 19/2013), con la grave dificultad práctica interpretativa que la aplicación de los preceptos genera a los sujetos obligados.

Es por eso que muchas leyes autonómicas vigentes en la materia han introducido previsiones que procuran añadir criterios de mayor concreción. Es el caso de la Ley 1/2014, de 24 de junio, de Transparencia Pública de Andalucía, cuyo artículo 30 c) aclara que «no se estimará como reelaboración que justifique la inadmisión la información que pueda obtenerse mediante un tratamiento informatizado de uso corriente», cosa que se equipara en sede normativa, pues, a la ausencia de una especial complejidad.

En este mismo sentido se refieren los artículos $30.1 \mathrm{c}$ ) de la Ley 8/2015, de 25 de marzo, de Transparencia de la Actividad Pública y Participación Ciudadana de Aragón, 43.2 c) de la Ley 12/2014, de 26 de diciembre, de transparencia y de acceso a la información pública del Parlamento de Canarias, $12.1 \mathrm{c}$ ) de la Ley 1/2018, de 21 de marzo, de Transparencia de la Actividad Pública de Cantabria, 31.1 c) de la Ley 


\section{El concepto de información pública ...}

4/2016, de 15 de diciembre, de Transparencia y Buen Gobierno de Castilla - La Mancha, 16.2 b) de la Ley 2/2015, de 2 de abril, de Transparencia, Buen Gobierno y Participación Ciudadana de la Comunidad Valenciana, 37 g) de la Ley Foral de Navarra 5/2018, de 17 de mayo, de Transparencia, acceso a la información pública y buen gobierno, o 26.4 c) de la Ley 12/2014, de 16 de diciembre, de Transparencia y Participación Ciudadana de la Comunidad Autónoma de la Región de Murcia.

El análisis objetivo de la condición de información pública, a los efectos de ejercer el derecho de acceso de acuerdo con las leyes 19/2013 y 19/2014, presupone al mismo tiempo ciertos matices o aclaraciones a tener en cuenta:

\subsection{Información más allá de la que debe ser publicada de forma activa.}

Primeramente, y en conexión con los deberes de transparencia activa, resulta esencial tener presente que la información pública objeto del derecho de acceso va más allá de la información pública que tiene que ser difundida en los portales de transparencia por parte de los sujetos obligados: desde un punto de vista objetivo porque el derecho de acceso abarca cualesquiera datos en poder de los sujetos obligados, tengan que ser objeto de publicidad activa o no (Resolución de la GAIP 93/2017), mientras que los contenidos que hay que publicar de forma activa constituyen un mínimo legal exigible de acuerdo con el Capítulo II del Título I de la Ley 19/2013 y el Título II de la Ley 19/2014; desde un punto de vista temporal porque, a diferencia de las obligaciones de publicidad activa, el derecho de acceso a la información pública tiene por objeto cualquier información pública, ya sea posterior como también anterior a la entrada en vigor de las leyes de transparencia (Resolución de la GAIP de la Reclamación 4/2016, o Resoluciones de la GAIP 45/2017 y 396/2017). De lo anterior se deriva necesariamente que el hecho de que una información no tenga que ser objeto de publicidad activa no la excluye per se del derecho de acceso (Resoluciones de la GAIP 335/2017 y 151/2018), y que si una información tiene que ser objeto de publicidad activa, con más razón tiene que serlo del derecho de acceso, en su caso (Resoluciones de la GAIP 100/2017 y 367/2017).

\subsection{Información más allá de cualquier procedimiento, registro o archivo.}

Tal y como hemos avanzado en la introducción, los regímenes de transparencia configuran un derecho de acceso a la información pública universal que es independiente del lugar en donde se encuentre ubicada la información.

En este sentido, la GAIP, en su dictamen 2/2016, aclaró que el acceso a la documentación depositada en los diversos archivos de Cataluña se rige integramente por la Ley 19/2014, desde el momento que no hace ninguna excepción en función de la ubicación en que se encuentre depositada la información pública. En la misma línea, el derecho de acceso a información puede ejercerse con independencia de si ésta se refiere o no a un procedimiento administrativo, teniendo en cuenta además que, en caso afirmativo, el derecho de 


\section{Oliver García Muñoz}

acceso legitima a pedir información relativa a procedimientos, tanto abiertos como cerrados o finalizados (Resolución de la GAIP 87/2017 y dictamen de la GAIP 1/2016).

Lo anterior no obsta a reconocer que la efectividad del derecho de acceso a la información pública requiere, como presupuesto básico, el cumplimiento adecuado por los sujetos obligados del deber administrativo de conservación y gestión adecuada de los documentos y de la información pública que garantice su localización y entrega, en el marco de las valoraciones documentales aprobadas ${ }^{12}$. El incumplimiento de este deber es indiciario de un funcionamiento deficiente de los servicios públicos responsables de la custodia y gestión de la información, vulnera tanto la normativa sobre transparencia como la de archivos, y constituye en definitiva un perjuicio directo en el ejercicio efectivo del derecho de acceso a la información pública, lo cual puede ser objeto de exigencia de responsabilidades administrativas (Resoluciones de la GAIP de la Reclamación 1/2016, de la Reclamación 28/2015, y Resoluciones 72/2016, 22/2017, 52/2017 o 157/2017).

\subsection{Exclusión de información auxiliar o de apoyo.}

Tanto el artículo 18.1 b) de la ley 19/2013 como el artículo 29.1 a) de la Ley 19/2014 vienen a excluir del concepto de «información pública» información que tenga carácter de auxiliar o de apoyo. El primero de los preceptos citados se refiere a información «contenida en notas, borradores, opiniones, resúmenes, comunicaciones e informes internos o entre órganos o entidades administrativas»; el segundo alude, en un semejante sentido, a «notas, borradores, resúmenes, opiniones o cualquier documento de trabajo interno sin relevancia o interés público».

De acuerdo con el criterio 6/2015 del CTBG, la enumeración se trata de «una mera ejemplificación que, en ningún caso, afecta a todos los conceptos enumerados sino a aquellos que tenga la condición principal de auxiliar o de apoyo» $y$, en este sentido, entiende que puede ser declarada inadmitida a trámite la solicitud de información en la que se den, entre otras, alguna de las siguientes circunstancias: 1. Cuando contenga opiniones o valoraciones personales del autor que no

\footnotetext{
${ }^{12}$ En Cataluña, la elaboración de las valoraciones documentales, de acuerdo con Ley 10/2001, de 13 de julio, de archivos y gestión de documentos, y con el Decreto 13/2008, de 22 de enero, sobre acceso, evaluación y elección de documentos, corresponde a la Comissió Nacional d'Accés, Avaluació i Tria documental (CNAATD) y, en caso de referirse a una serie documental pública, requiere que la persona titular de la consejería de la Administración de la Generalitat de Cataluña competente en materia de cultura, mediante orden, apruebe las tablas de evaluación y acceso documental propuestas por la referida CNAATD.

En la Administración General del Estado, el procedimiento de valoración documental se tramita a través de la Comisión Calificadora de Documentos Administrativos del Ministerio del Interior, de acuerdo con lo que dispone el Real Decreto 1708/2011, de 18 de noviembre, por el que se establece el Sistema Español de Archivos y se regula el Sistema de Archivos de la Administración General del Estado y de sus Organismos Públicos y su régimen de acceso. La Orden INT/533/2014, de 19 de marzo, tiene por objeto regular las funciones, composición y funcionamiento de dicha Comisión Calificadora, creada mediante Orden del mismo Ministerio del Interior de 21 de diciembre de 2000.
} 


\section{El concepło de información pública ...}

manifiesten la posición de un órgano o entidad; 2 . Cuando lo solicitado sea un texto preliminar o borrador sin la consideración de final; 3. Cuando se trate de información preparatoria de la actividad del órgano o entidad que recibe la solicitud; 4. Cuando la solicitud se refiera a comunicaciones internas que no constituyan trámites del procedimiento; o 5 . Cuando se trate de informes no preceptivos y que no sean incorporados como motivación de una decisión final.

En cualquier caso, según el CTBG, la información auxiliar no es el equivalente a información de valor provisional, por lo que los documentos a que se refiere el art. 18.1.b) de la Ley 19/2013 son los que tienen un ámbito exclusivamente interno (resoluciones del CTBG R/0290/2018 y R/0296/2018). Además, «debe ser el contenido y no la denominación del documento lo determinante para la aplicación de la referida causa de inadmisión» (resolución del CTBG R/0169/2018).

La causa de inadmisión prevista en la norma legal catalana parece restringir en mayor medida su ámbito de aplicación cuando añade la condición consistente en que este tipo de información, en cualquier caso, haya de carecer de «relevancia o interés público», previsión que, por lo tanto, parece ser más proclive a garantizar el acceso efectivo a información pública. La doctrina de la GAIP ha venido entendiendo que carecen de dicha relevancia o interés (i) las opiniones o valoraciones personales que no manifiesten la posición formal de un órgano o servicio; (ii) los documentos de carácter preliminar o provisional, que no revistan la consideración de final o sean de uso interno (Resolución de la GAIP 49/2017 - acta del órgano colegiado no aprobada); (iii) el carácter preparatorio de la actividad del órgano o entidad que recibe la solicitud (Resolución de la GAIP 49/2017 borradores o propuestas-); o (iv) las comunicaciones informales, internas 0 externas, o que se refieran a aspectos organizativos, o que no constituyan trámites del procedimiento.

\section{PERSPECTIVA SUBJETIVA DEL CONCEPTO DE «INFORMACIÓN PÚBLICA».}

Es información pública aquella que obra «en poder de alguno de los sujetos incluidos en el ámbito de aplicación de este título y que hayan sido elaborados o adquiridos en el ejercicio de sus funciones», en términos de la Ley 19/2013.

\subsection{Sujetos obligados a tramitar las solicitudes de acceso.}

En primer lugar, la amplitud de los sujetos incluidos en el título I de dicha ley (que tiene por título «transparencia de la actividad pública») no sólo abarca el concepto estricto de Administración pública que ofrece el artículo 2.3 tanto de la Ley 39/2015, del 1 de octubre, del procedimiento administrativo común de las administraciones públicas (Ley 39/2015), como de la Ley 40/2015, de 1 de octubre, 


\section{Oliver García Muñoz}

de Régimen Jurídico del Sector Público (Ley 40/2015), sino que alcanza a muchos otros sujetos, instituciones y autoridades públicas ${ }^{13}$ :

Con sumisión plena, las universidades públicas, las fundaciones del sector público, las entidades gestoras y servicios comunes de la Seguridad Social, las mutuas de accidentes de trabajo y enfermedades profesionales colaboradoras de la Seguridad Social, los organismos autónomos, agencias estatales, entidades públicas empresariales y entidades de derecho público que, con independencia funcional o con una especial autonomía reconocida por la ley, tengan atribuidas funciones de regulación o supervisión de carácter externo sobre un determinado sector o actividad, así como las asociaciones constituidas por los sujetos incluidos y las sociedades mercantiles por los mismos participadas, de forma directa o indirecta, en más del 50 por 100 de su capital.

Con sumisión en relación sólo con sus actividades sujetas a Derecho Administrativo: las corporaciones de derecho público, la Casa de su Majestad el Rey, el Congreso de los Diputados, el Senado, el Tribunal Constitucional, el Consejo General del Poder Judicial, el Banco de España, el Consejo de Estado, el Defensor del Pueblo, el Tribunal de Cuentas, el Consejo Económico y Social y las instituciones autonómicas análogas.

Por su parte la Ley 19/2014 se refiere a «la información elaborada por la Administración y la que ésta tiene en su poder como consecuencia de su actividad o del ejercicio de sus funciones».

De acuerdo con el artículo 2 f) de la Ley 19/2014, el concepto de Administración pública a estos efectos es también mucho más amplio en comparación con la definición clásica del artículo 2.3 de las leyes 39/2015 y 40/2015, dado que aquel concepto incluye también las sociedades con participación mayoritaria o vinculadas, fundaciones del sector público, entidades de derecho público que actúan con independencia funcional o con una autonomía especial reconocida por ley que ejercen funciones de regulación o supervisión externa sobre un determinado sector $\circ$ actividad, las instituciones estatutarias previstas en el Capítulo V del Título II del Estatuto de autonomía de Cataluña (el Consejo de Garantías Estatutarias, el Síndic de Greuges, la Sindicatura de Comptes y el Consejo del Audiovisual de Cataluña), colegios profesionales y corporaciones de derecho público -«en aquello que afecta al ejercicio de sus funciones públicas»-, consorcios $u$ otras formas asociativas $-y$ sus entes vinculados y sociedades mercantiles en los cuales participa de manera mayoritaria alguna de estas

\footnotetext{
${ }^{13}$ Artículos 2.3 de la Ley 39/2015 y de la Ley 40/2015: «Tienen la consideración de Administraciones Públicas la Administración General del Estado, las Administraciones de las Comunidades Autónomas, las Entidades que integran la Administración Local, así como los organismos públicos y entidades de derecho público previstos en la letra a) del apartado 2 anterior» («cualesquiera organismos públicos y entidades de derecho público vinculados o dependientes de las Administraciones Públicas»).
} 


\section{El concepto de información pública ...}

administraciones- y las universidades públicas de Cataluña y entes que dependen o están vinculados o participados por las mismas -incluidas las sociedades mercantiles, las fundaciones y otros entes instrumentales-.

\subsection{Criterios de atribución de la competencia para tramitar y resolver las solicitudes de acceso.}

El artículo 1.2.b del Convenio CE 205 alcanza a «toda la información registrada en cualquier forma, elaborada o recibida y en poder de las autoridades públicas». Es decir, también incluye la simplemente recibida y en su poder.

Esta es también la solución adoptada por el Reglamento 1049/2001, según el cual el derecho de acceso se refiere a todos los documentos que obren en poder de las instituciones, es decir, no solo los que hayan sido elaborados por éstas, sino también los que hayan recibido y estén en su posesión.

En esta misma línea la Ley 19/2014, en su artículo 2.b), define «información pública» la «elaborada por la Administración y la que ésta tiene en su poder como consecuencia de su actividad o del ejercicio de sus funciones, incluida la que le suministran los otros sujetos obligados».

La normativa acabada de citar tiene en común el hecho de no recoger la llamada «regla del autor», según la cual, la solicitud debe dirigirse directamente al autor del documento, y no a la institución u organismo que lo posea.

Así pues, de acuerdo con esta normativa, todos los documentos «en poder» de los sujetos obligados a atender las solicitudes de acceso a información deben ser accesibles al público, de tal forma que las administraciones que reciban una solicitud de acceso a información pública que tengan en su poder están obligadas a atenderlas, tramitarlas y resolverlas, con independencia de quien haya elaborado la información o de quien la hayan recibido.

En este sentido se pronuncia expresamente la GAIP en su dictamen 3/2016, en el que, entre otros aspectos, infiere de lo anterior que los sujetos obligados sólo pueden eximirse de dar trámite a las solicitudes de acceso a información en los casos en los que ésta no se encuentre en su poder, supuesto éste en el que la solicitud debe derivarse al sujeto obligado que detente o posea la información solicitada, de acuerdo con lo que establece al respecto el artículo 30 de la Ley $19 / 2014$.

En cambio la Ley 19/2013 ha optado por recoger la «regla del autor», pues al definir en su artículo 13 el concepto de información pública, no solo se refiere a la que obre «en poder de alguno de los sujetos incluidos en el ámbito de aplicación de este título», sino que, además, añade, como requisito adicional, «y que hayan sido elaborados o adquiridos en el ejercicio de sus funciones.» 


\section{Oliver García Muñoz}

De acuerdo con esta definición, el artículo 19.4 de la Ley 19/2013 prescribe que en los casos en los que la información objeto de solicitud, «aun obrando en poder del sujeto al que se dirige, haya sido elaborada o generada en su integridad o parte principal por otro, se le remitirá la solicitud a éste para que decida sobre el acceso». Por todo ello hay que concluir que, de acuerdo con la ley estatal básica, las administraciones no son competentes para tramitar y resolver aquellas solicitudes de acceso a información que, no sólo no tengan en su poder, sino tampoco la que, incluso teniéndola a su disposición, haya sido elaborada o generada, en su parte principal, por otra administración o sujeto obligado.

La solución escogida por la Ley 19/2013 parece pues exigir no solo que la información esté en poder del sujeto obligado, sino que éste sea también quien la haya elaborado o «adquirido». Sin perjuicio de que el término adquirido no es seguramente el más preciso, dicha opción parece dejar fuera la información que puede estar en posesión de un sujeto obligado, pero que no ha sido elaborada ni ha sido adquirida por él, criterio que, en palabras de Piñar Mañas ${ }^{14}$, «no parece acertado».

\subsection{Información «en poder» de los sujetos obligados: concepto amplio.}

En cualquier caso, es necesario que las Administraciones públicas se encuentren «en poder» de la información, con independencia de que su posesión sea directa o indirecta.

Tal y como expresamente ha reconocido la GAIP, el artículo 2.b de la Ley 19/2014 habla de información «en poder» de la Administración, y no en posesión: «la posesión es una noción que hace referencia a la disponibilidad material de la información, mientras que la expresión «en poder» va más allá y alcanza también a la información que no se encuentra materialmente en manos [de la Administración], pero que [éstal tiene potestad o poder jurídico para exigir que le sea entregada como consecuencia de su actividad o en ejercicio de sus funciones.» (Resolución de la GAIP 156/2018, entre otras).

Por lo tanto, «información pública» no sólo lo son los datos que se encuentran dentro de la órbita material de actuación de un ente público obligado, sino también los que poseen las personas físicas y jurídicas que, de acuerdo con el artículo 4 de la Ley 19/2013, se encuentran obligadas a suministrar información, previo requerimiento -requerimiento exigido explícitamente por el precepto de la ley estatal-, a los sujetos obligados por la ley y a los cuales se encuentran vinculados con motivo de prestar servicios públicos o ejercer potestades administrativas ${ }^{15}$.

\footnotetext{
${ }^{14}$ Piñar Mañas, José Luis, "Transparencia y derecho de acceso a la información pública. Algunas reflexiones en torno al derecho de acceso en la Ley 19/2013, de transparencia, acceso a la información y buen gobierno", en Revista catalana de dret públic, núm. 49, 2014, p. 10.

${ }^{15}$ Vale la pena citar aquí el artículo 49.2 de la Ley 16/1985, de 25 de junio, del patrimonio histórico español, según el cual «forman parte del Patrimonio Documental los documentos de cualquier época generados, conservados o reunidos en el ejercicio de su función por cualquier organismo o entidad
} 


\section{El concepto de información pública ...}

Este deber de los terceros prestatarios se concreta en la obligación de suministrar a los sujetos obligados «toda la información necesaria» a fin de que estos últimos puedan dar cumplimiento a las obligaciones previstas en el título primero de la Ley 19/2013 (publicidad activa y derecho de acceso); y es que en ningún caso la solicitud de acceso a información pública debe dirigirse al prestador privado, sino, en todo caso, a la Administración titular del servicio por aquél gestionado, que es la que tiene la competencia y obligación de tramitar y resolver la solicitud de acceso.

De forma similar, aunque con mayor alcance, la Ley 19/2014 viene a incluir también en el concepto de información pública los datos materialmente detenidos por terceras personas particulares que se vinculan 0 relacionan con las Administraciones públicas sujetas a sus prescripciones con motivo de alguno de los títulos a los cuales se refieren las letras c) y d) del artículo 3.1 de la Ley 19/2014, es decir, con motivo de ejercer funciones públicas o potestades administrativas, de prestar un servicio público, de llevar a cabo servicios de interés general o universal, o incluso también de recibir cualquier ayuda o financiación pública, supuesto este último no contemplado en cambio en la norma básica estatal. En el caso de la norma catalana, no se prevé explícitamente en su articulado la necesidad de requerimiento previo al efecto, aunque debe deducirse igualmente.

En estos casos la información pasará a considerarse pública en la medida en que haya sido o tenga que ser comunicada por los terceros a la Administración pública, en tanto que ésta conserva el control o la responsabilidad de las potestades, los servicios o los fondos públicos de su titularidad ${ }^{16}$, lo cual la faculta, e incluso la compele, a exigir a los terceros gestores, prestatarios o beneficiarios la entrega material de la información, con la finalidad de poder garantizar a la ciudadanía el ejercicio del derecho en su acceso, de acuerdo con lo que dispone el apartado $2^{\circ}$ del artículo 3 de la Ley 19/2014 (Resolución de la GAIP de la Reclamación 299/2016).

A su vez, los terceros, con fundamento en este mismo precepto, quedan obligados a atender el requerimiento formulado por la Administración con la cual se vinculan y a facilitarle los datos solicitados (dictamen de la GAIP 4/2016 y Resoluciones de la GAIP 64/2017 o 351/2017) ${ }^{17}$. No obstante, cabe hacer un par de presiones al respecto:

de carácter público, por las personas jurídicas en cuyo capital participe mayoritariamente el Estado u otras entidades públicas y por las personas privadas, físicas o juridicas, gestoras de servicios públicos en lo relacionado con la gestión de dichos Servicios.»

${ }_{16}$ «El derecho a saber, a tener conocimiento de aquello que es de «interés público» (esto es, de lo que permanece de alguna u otra manera vinculado o bajo el control de los sujetos obligados) deriva, sin duda, de los principios democrático y de publicidad, transparencia y participación, que imponen el ejercicio visible del poder (...)». Informe de la Oficina Antifrau de Cataluña, $2^{a}$ edición, diciembre 2014, Derecho de acceso a la información pública y transparencia. (p. 109).

(https://www.antifrau.cat/images/web/docs/publicacions/estudis_integricat/o004esp_estudis_inte gricat_2a_edicio_15_12_2014.pdf)

${ }^{17}$ En este sentido, son muchas las resoluciones de la GAIP que tienen por objeto el acceso a estudios o informes previamente entregados a la Administración por parte de entidades adjudicatarias de 


\section{Oliver García Muñoz}

Por un lado, dicha obligación les es exigible tan sólo en relación con la información generada a partir de la entrada en vigor de las leyes de transparencia, y no antes (Resoluciones de la GAIP 351/2017 o 362/2018).

Por otro, y al efecto de dar cumplimiento a dicha obligación, los prestadores privados de servicios públicos deben formalizar previamente un contrato de gestión de servicio público en aplicación de lo dispuesto en el artículo 3.5 de la Ley 19/2014, según el cual "los contratos del sector público tienen que incluir las obligaciones de los adjudicatarios de facilitar información establecidas por esta ley, sin perjuicio del cumplimiento de las obligaciones de transparencia".

Con todo, huelga decir que los sujetos a los que se refieren el artículo 3 de la Ley 19/2013 y el artículo 3.4 de la Ley 19/2014 -partidos políticos, organizaciones sindicales y empresariales, así como entidades privadas que perciban subvenciones o ayudas públicas en los términos fijados por dichos preceptos-, ni están sujetos al deber de atender solicitudes de acceso a información pública, ni pesa sobre ellos el deber de dar traslado de información solicitada a las administraciones o sujetos obligados por el derecho de acceso, puesto que a dichos sujetos únicamente les es de aplicación el capítulo II del Título I de la Ley 13/2019 y el Título II de la Ley 19/2014, relativos a los deberes de publicar de forma activa determinada información pública (publicidad activa).

\section{AUSENCIA DE CONDICIÓN DE «INFORMACIÓN PÚBLICA».}

Con todo, ¿qué ocurre cuando se pide acceder a información que no tiene la consideración de información pública, por faltar la concurrencia de alguno de los elementos, objetivos o subjetivos, definidores del concepto?

Si los datos de interés no constituyen «información pública», en los términos apuntados más arriba, las leyes de transparencia no son aplicables y, por lo tanto, nos situamos fuera del régimen que en las mismas se regula, en relación con el derecho de acceso a la información pública.

De acuerdo con las consideraciones expresamente manifestadas en el apartado Il.1.2 de la memoria doctrinal de la GAIP correspondiente al año 2017, en estos casos procederá la inadmisibilidad de la solicitud: «además de las causas concretas de inadmisibilidad de las solicitudes de información pública (contenidas

servicios públicos (Resoluciones de la GAIP 40/2017 o 174/2017), o bien a documentación o datos que se encuentran todavía en manos de los terceros y que la Administración con la cual se relacionan deberá requerir para poder dar cumplimiento a una eventual estimación de una solicitud de acceso (Resoluciones de la GAIP de las Reclamaciones 7/2016 y 18/2016 -documentación justificativa de subvenciones otorgadas-, de la Reclamación 142/2016 - datos sobre el número de trabajadores, condiciones laborales y trabajos subcontratados en la prestación de servicios públicos externalizados; o de la Reclamación 58/2016, y Resolución de la GAIP 362/2018 - datos relativos a retribuciones y dietas anuales percibidas por determinados cargos directivos de equipamientos sanitarios 0 culturales). 


\section{El concepło de información pública ...}

explícitamente en el artículo 29 de la Ley 19/2014), también constituye un motivo evidente de inadmisibilidad de las solicitudes el hecho de que se planteen al margen del derecho de acceso a la información pública, bien sea porque lo solicitado no es información pública, o bien porque la entidad a quien se solicita no es un sujeto obligado por el derecho de acceso a la información pública.» ${ }^{18}$

Muestra del efecto de inadmisibilidad de las solicitudes cuyo objeto no encaja en el concepto de «información pública» lo son las causas de inadmisión que tanto la Ley estatal 19/2013 -artículo 18- como la Ley catalana 19/2014 -artículo 29prevén, en relación al objeto del derecho de acceso, analizadas en este trabajo.

A diferencia de la apreciación de los límites al derecho de acceso a información pública (previstos en los artículos 14 y 15 de la Ley 19/2013, y 21, 23 y 24 de la Ley 19/2014), hay que tener en cuenta que la apreciación de una causa de inadmisión total o parcial de la solicitud de acceso implica no entrar en el fondo de la petición, que se excluye de la tramitación, para lo cual es necesario dictar igualmente una resolución motivada que hay que notificar a la persona solicitante.

Además, y también difiriendo de los límites que pudiesen ser invocados y aplicados en la resolución de las solicitudes de acceso, que se caracterizan por una configuración y conceptualización esencialmente juridicas, la apreciación de una inadmisión no requiere de ninguna ponderación respecto de derechos o intereses concurrentes en el acceso. Ello es así porque las causas de inadmisibilidad suelen tener una definición básicamente material, y por lo tanto su ponderación con derechos e intereses favorables al acceso es prácticamente inviable (entre otras, véase la Resolución de la GAIP 78/2017). Este mismo razonamiento conduce a negar la posibilidad de invocar o apreciar un motivo de inadmisión de la solicitud una vez transcurrido el plazo para resolverla. Así, en la Resolución de la GAIP 388/2017, y de acuerdo con lo que dispone el artículo 35.2 de la Ley 19/2014, expresamente se concluye que, una vez finalizado el plazo para resolver, no parece que pueda ser opuesta a la estimación del acceso ninguna otra circunstancia más que la concurrencia de un límite al derecho de acceso, de los legalmente establecidos, en la medida que el bien jurídico protegido con la causa de inadmisión no lo constituyen derechos de terceras personas sino la eficaz organización del trabajo de las administraciones, que pueden así oponerse a las solicitudes que la perturben. ${ }^{19}$

\footnotetext{
${ }^{18}$ En este sentido, véase, entre otras, las Resoluciones de la GAIP de la Reclamación 27/2016 y de la Reclamación 68/2016 (información inexistente), y las Resoluciones de la GAIP 109/2017 (información futura), 75/2017 y 387/2017 (información privada en manos de una federación deportiva, que escapa del control de las Administraciones públicas), o 124/2017 (información en poder de los órganos judiciales, fuera del ámbito subjetivo de aplicación de los regímenes de transparencia analizados).

${ }_{19}$ Véase en este punto Fernández Salmerón, M. y Sierra Rodríguez, J. 2019. «Inadmisión y necesidad de reelaboración ante el derecho de acceso a la información pública», Revista de Estudios de la Administración local y autonómica, 11: 56-74.
} 


\section{Oliver García Muñoz}

No obstante, y con independencia de las causa de inadmisión previstas en el ordenamiento, huelga decir que es habitual que los términos en los que se formula una solicitud de acceso a información pública sean imprecisos o genéricos, de tal forma que dificulten la obtención de la información pública concreta a la cual se pretende tener acceso. En estos casos claro está que el carácter indeterminado de la solicitud no impide necesariamente que su objeto tenga la condición de información pública, sino que más bien la solución prevista por el ordenamiento jurídico (artículos 19.2 Ley 19/2013 y 28 de la Ley 19/2014) pasa por tener que dirigir la Administración a la persona solicitante un requerimiento de subsanación de su solicitud, de tal forma que le permita poder concretar su objeto (Resolución de la GAIP 161/2017).

\section{CONCLUSIONES.}

El concepto de «información pública», a los efectos del objeto del derecho de acceso regulado en las leyes de transparencia, goza de una significativa amplitud, puesto que no solo incluye datos documentados o recogidos en un soporte material concreto, sino también informaciones de obtención indirecta, por encontrarse dispersas; el concepto abarca toda la información en manos de los sujetos obligados, más allá de la información que debe ser publicada de forma activa, y con independencia de que la información se encuentre o no en un procedimiento, en un registro o en un archivo.

Con todo, no podemos hablar de «información pública» cuando su obtención implica la necesidad de «elaborar» o generar propiamente los datos solicitados, cuando son inexistentes en la esfera de control de la Administración responsable.

Pero debemos aceptar que los sujetos obligados están compelidos a realizar una cierta tarea de mínima elaboración o simple tratamiento previo de búsqueda, recopilación, sistematización, refundición, deducción o mínimo análisis de datos con la finalidad de poder dar satisfacción al derecho de las personas a su acceso.

No obstante, el deber de las Administraciones de buscar o recopilar la información solicitada no puede ser en ningún caso de exigencia ilimitada, y encuentra su límite en las causas de inadmisión que aluden especialmente a la «información para cuya divulgación sea necesaria una acción previa de reelaboración», o a «una tarea compleja de elaboración o reelaboración», según la norma aplicable, conceptos éstos que adolecen de una importante indeterminación, por lo que deben ser interpretados a la luz de la doctrina de los respectivos órganos garantes del correcto cumplimiento de las obligaciones que comporta el derecho de acceso a la información pública para los sujetos obligados. 


\section{El concepło de información pública ...}

\section{BIBLIOGRAFÍA.}

Bandrés Sánchez-Cruzat, J. M. (prólogo) y otros autores. 2017. Los limites al derecho de acceso a la información pública. Madrid: Instituto Nacional de Administración Pública. Colección: monografias.

Barredo, C., Descalzo, A., Guichot, E., Hogué, C., Palomar, A. 2014, Transparencia, Acceso a la Información Pública y Buen Gobierno. Estudio de la Ley 19/2013, de 9 de diciembre. Madrid: Tecnos.

Barrero Rodríguez, C. 2017. «Las causas de inadmisión de las solicitudes de acceso a la información; en particular, la doctrina de las autoridades independientes». Revista General de Derecho Administrativo, 46:1-46.

Cerrillo i Martínez, Agustí, i Ponce i Solé, Juli (Coord.). 2015. Transparencia, Acceso a la Información Pública y Buen Gobierno. Comentarios a la Ley 19/2014, de 29 de diciembre, Barcelona: UOC, en coedición con la Escola d'Administració Pública de Catalunya.

Fernández Ramos, S. y Pérez Monguió, J.M. 2014. Transparencia, Acceso a la información pública y Buen Gobierno. Ley 19/2013, de 9 de diciembre. Cizur Menor: Aranzadi.

Fernández Salmerón, M. y Sierra Rodríguez, J. 2019. «Inadmisión y necesidad de reelaboración ante el derecho de acceso a la información pública», Revista de Estudios de la Administración local y autonómica, 11: 56-74.

Guichot Reina, E. 2011. Transparencia y acceso a la información pública en España: análisis y propuestas legislativas, Madrid: Fundación Alternativas (Documento de trabajo 170/2011).

Hernández Godínez, A. 2010. El acceso a la información pública. Evolución y consolidación de un derecho fundamental de nueva generación. Madrid: Universidad Carlos III (tesis doctoral).

Meseguer Yebra, J. 2014. «El procedimiento administrativo para el ejercicio del derecho al acceso a la información pública», Revista jurídica de Castilla y León, 33: 1-34.

Mir Puigpelat, O. 2017. «El acceso a la información pública en la legislación española de transparencia: crónica de un cambio de paradigma», Revista Catalana de dret públic, 55: 48-66.

Piñar Mañas, J. L. 2014. «Transparencia y derecho de acceso a la información pública. Algunas reflexiones en torno al derecho de acceso en la Ley 19/2013, de transparencia, acceso a la información y buen gobierno», Revista catalana de dret públic, 49: 1-19. 


\section{Oliver García Muñoz}

Rams Ramos, L. 2016. «El procedimiento de ejercicio del derecho de acceso a la información pública», Revista General de Derecho Administrativo, 41: 1-46.

Sánchez de Diego Fernández de la Riva, M. 2008. «Un derecho fundamental a acceder a la información pública», El derecho de acceso a la información pública, 7-41.

Velasco Rico, C. I. 2013. «Análisis en clave competencial del Proyecto de Ley estatal sobre Transparencia, Acceso a la Información Pública y Buen Gobierno», Revista d'Estudis Autonòmics i Federals, 17: 279-328.

Velasco Rico, C. I. 2015. «Reconocimiento y protección del derecho de acceso a los documentos públicos en Quebec. Especial referencia a la Comisión de Acceso a la Información», Revista catalana de dret públic, 50: 121-140. 